\title{
Cortical dysarthria and dysprosody of speech
}

\author{
C. W. M. WHITTY \\ From the Department of Neurology, United Oxford Hospitals
}

The nature and indeed the existence of a syndrome of cortical dysarthria has been the subject of considerable argument in the past 50 years: some of it acrimonious, and much of it dissolving into semantic discussion. The matter has been concisely reviewed by Critchley (1952) in considering articulatory defects in aphasia. There is no doubt that whatever the descriptive term used occasional cases occur in which a known and limited cortical lesion produces a change in speech which is largely confined to articulation and presents as dysarthria with little or no dysphasic element.

The case reported here showed just such a speech defect, and in addition a change in 'accentation' and melody (dysprosody) of speech, with alteration in the use of gesture which gave the impression of someone talking a foreign language. The cause of these symptoms appeared to be an intracerebral haemorrhage from a small angioma in the territory of the left middle cerebral artery. Angiography and operative treatment of the clot allowed an unusually precise localization of the lesion. The anatomical information and unusual clinical features are thought to justify a detailed report.

\section{CASE REPORT}

A 27-year-old healthy married woman noticed the sudden onset of numbness in the right hand while out walking about 4 p.m. one afternoon. An hour or so later she also noticed that her right face seemed weak and she dribbled from that corner of her mouth. Others said that her speech was slurred, though it was intelligible and she used correct words. By 7 p.m., when she was admitted to hospital, she found herself unable to utter any words, even attempts at phonation producing no sounds. The numbness of the hand had decreased but voluntary movement was impaired. The facial weakness was also better and she no longer dribbled.

Subsequent enquiry revealed a past history of migraine from the age of 12 to about 23 years. Attacks were ushered in with flashing lights and stars in either field of vision, followed by headache, normally bifrontal and throbbing. Occasionally it was lateralized and had then occurred on hoth right and left sides. She also had frequent hay-fever and associated with this would get occasional transient headaches alwavs localized to the left parietal region. She had had no other illness apart from the usual childhood ailments.

She was an only child. There was no family history of migraine, but her father had had severe hay-fever. He had died at the age of 35 of peritonitis. Her mother was alive and well. The patient had been married for six years and had no children. She had been educated entirely in England as had her parents and husband. She had learnt elementary French at school and had worked as a secretary until her marriage. She spoke no foreign language. She was right-handed and there was no family history of left-handedness.

On examination about four hours after the onset of her symptoms she was alert and fully cooperative but very frightened. She would make no attempt to speak or phonate but indicated answers to questions by head movements. There was no facial weakness but voluntary movements were impaired on the right. She could not protrude her tongue nor elevate the palate to order. There was some reduction of sensory appreciation both to light touch and pin-prick in the right arm. Although there was no apparent weakness in this limb in spontaneous movements, she was unable to carry out movements on request nor could she imitate them. When seen three hours later she could speak and used words correctly but speech was slow, hesitant, and slurred. She could now move the palate and swallow to order, but lip and tongue movements were incorrectly executed and she could not protrude the tongue or make named sounds on request.

Some 36 hours later she had no objective sensory abnormality at all. Spontaneous movements of arms, face, and tongue were normal, but there was still slight dyspraxia to requested or imitated movements of lips and tongue. Her rate of spontaneous speech was also now normal. However, she spoke with a foreign accent which several independent witnesses regarded as German. Her speech was also emphasized by gesture of the hands which was unusual for her. There was some dysarthric slurring of words, 'rs' being especially liable to mispronunciation, occasional misuse of syllables, and very occasional hesitation and apparent searching for the right word. Attempts at such standard phrases as 'West Registrar Street' and 'ancient and honourable institution' were definitely dysarthric. Nevertheless speech was free, appropriate, and completely intelligible. Its most striking characteristic was its apparently foreign accentation, an impression which was strengthened by the dysarthria. In naming a series of objects she made mistakes in about one in ten. They were usually approximations to the correct word, e.g., spring for string, bungle for buckle, watch-trap for watch-strap, etc., and mistakes were realized and attempts at correction made. There was no evidence of any receptive dysphasia as shown by replies to questions and the execution of simple and complex verbal commands. Reading aloud was correctly done and 
she repeated the sense of the passage accurately. Writing to dictation and copying of printed sentences showed occasional mistakes-omission of words or syllables. This was much less so in spontaneous writing. Simple mental arithmetic was unimpaired. In written calculations, addition and subtraction, she made occasional mistakes, but these were considered dysgraphic rather than dyscalculic. Spontaneous drawings of a clock-face and a house and copying of designs were correctly done. In summary, she had a minimal motor dysphasia with slight tonguelip dyspraxia; but more marked abnormalities were a dysarthria and a most striking change in accentation and melody of speech. This condition remained substantially unchanged until exploratory craniotomy 10 days later.

Investigations included normal findings in cerebrospinal fluid, skull radiographs, full blood count and sedementation rate, and serology in blood and cerebrospinal fluid. An electroencephalogram showed a slow wave abnormality in the left fronto-temporal region. A left

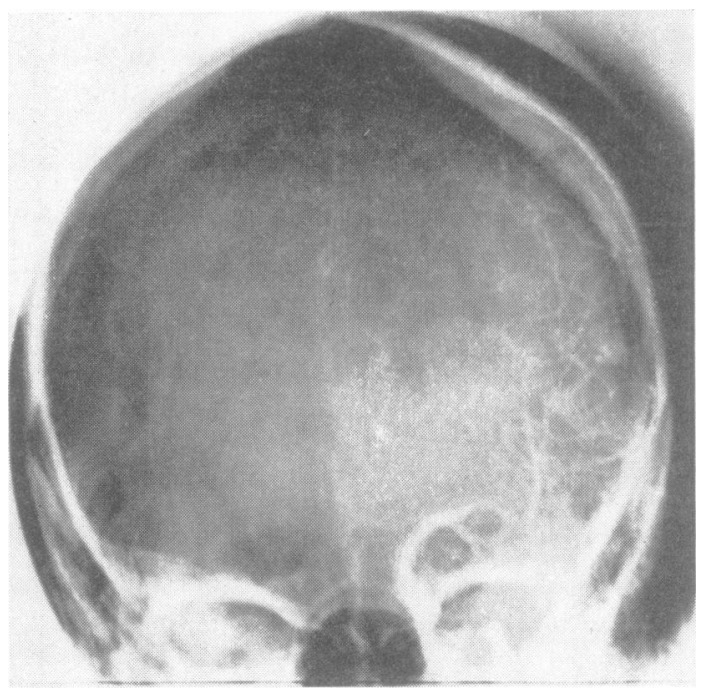

FIG. 1. Left carotid angiogram (postero-anterior view).

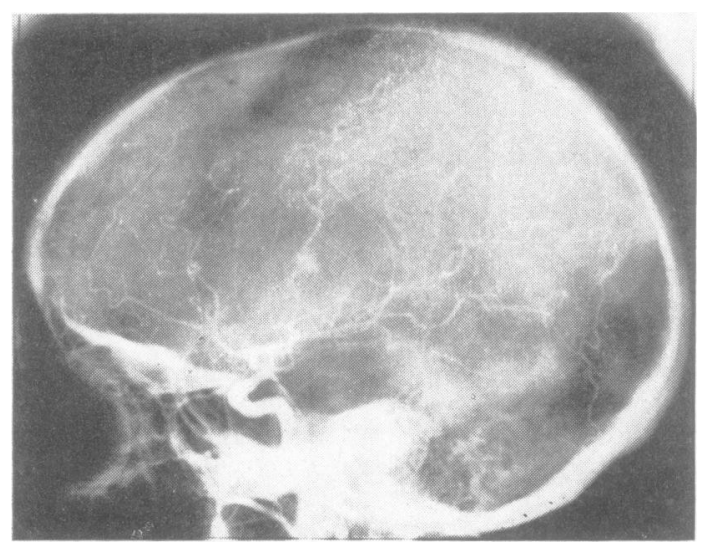

FIG. 2. Left carotid angiogram (lateral view). carotid angiogram demonstrated a small angiomato $\bar{R}$ malformation arising from an anterior branch of the middle cerebral artery in the pre-Rolandic area and jus above the Sylvian fissure. It appeared to be superficiaf and local vessel displacement suggested an intracerebra clot (Figs. 1 and 2). These findings were confirmed ag operation, when Mr. J. M. Potter noted 'a little increased vascularity in the immediate vicinity of the Roland fissure, $1 \mathrm{~cm}$. above the Sylvian fissure. ... The small are of cortex bearing the vascular malformation was corr. pletely excised. This measured approximately $1 \mathrm{~cm}$. $1 \mathrm{~cm}$. by $0.75 \mathrm{~cm}$. Beneath was a clot cavity $8 \mathrm{~cm}$. antero $?$ posteriorly by $4 \mathrm{~cm}$. by $4 \mathrm{~cm}$. which was evacuated Her post-operative course was uneventful. She went home eight days after the operation and at that time had no nominal dysphasia and no dyspraxia. She still spoke with a foreign intonation and slight dysarthria. Her use of gesture was still considered excessive for her. When examined one month later, seven weeks after the onseb her speech was normal in all respects. Her 'foreign' accent had disappeared. Writing spontaneously and $\vec{\theta}$ dictation was also normal. She regarded herself as con? pletely normal as did her relatives.

\section{DISCUSSION}

The study of aphasia is a fertile field for theoretiç and interpretive argument, in which the contengees, do not always define their terms. The resulting fusion is nevertheless more apparent than real. कीhe evidence is still convincing for two broad types speech defect associated with cortical lesions: ons which the trouble is predominantly motor or pressive, the other where comprehension of wis and their meaning is chiefly impaired. Each tend to be associated also with a particular site of lesirg the first a limited area at the base of the Rolandie sulcus and the posterior end of the third and second frontal convolutions; the second involving a rathe less defined area of the temporo-parieto-occipita cortex. There is little to contradict and much to con firm the earlier views postulating Broca's and Wernicke's types of dysphasia (Hécaen and Ange lergues, 1964). Further more detailed analysis ce tainly reveals a number of varieties of both types, ang instances in which both expressive and receptive lo are combined. It is to be expected also that if compre hension of words is faulty some aspects of motor es pression will be secondarily affected, just as it will be if that part of the body scheme concerned with lips and tongue is diseased. When, however, full anatomis: cal information of the site of a lesion is available, an this is unhappily infrequent, such mixed and varie gated cases still support the broad division, and the last resort it is the evidence of relatively pure types of dysphasia and their anatomical correlation which is crucial.

กิ

A consideration of the cases of localized brain wounds causing speech defects reported by Marie and 
Foix (1917) and Russell and Espir (1961) lends ample support to this basic classification, even though the anatomical evidence in many of such cases is not as full as we would like. Within the group of mainly motor defects there are a number of cases in which throughout their disability or at some stage of it, the speech difficulty is best described as dysarthric. Marie and Foix used the term 'anarthric syndromes' for these: and in most severe examples there was initially a complete inability to utter words. Later, however, mispronunciation of words and the inability to master the French equivalent of our own test phrases for dysarthria made 'dysarthric' the more appropriate adjective. Marie (1906) originally insisted on a pure anarthria whose anatomical substrate lay in a 'lenticular zone' of frontal cortex and sub-cortex between the head of the caudate and the posterior end of the lenticular nucleus. This speech defect he considered had no necessary connexion with aphasia. The latter was for him always a comprehension difficulty and he regarded Broca's 'aphemia' as a mixture of anarthria and aphasia. The distinction is one of definition. Despite his previous view, in his joint paper with Foix in 1917 entitled 'Aphasias of war', anarthric syndromes are included. Henschen's (1922) violent objection to Marie's terminology seems to be largely semantic. If dysarthria is defined as due to a fault of bulbar innervation, then dysarthria from a purely cortical lesion must be a contradiction. But dysarthria is primarily a description of a mode of speech. In this sense some of Marie's cases are excellent examples of dysarthria. The same can be said of some of the cases recorded by Russell and Espir (1961) and Bay (1962): and in all three series the anatomical location of lesions is strikingly consistent. All are grouped towards the lower end of the Rolandic fissure, and most are rather more anterior than posterior to it. The term 'cortical dysarthria' for these cases seems descriptively accurate and appropriate. When it is used, it is common to segregate it from dysphasia proper (Bay, 1964). Such a usage implies, as it did for Marie, that dysphasia must by definition entail some lack of comprehension of the meaning of words. This is logical but obscurity may result if the term 'motor dysphasia' is also retained. Henschen (1922) suggested that Marie's use of anarthria was a source of confusion and should be abandoned. In fact it might add more to clarity if the term motor dysphasia were given up in favour of cortical dysarthria or dyspraxic dysarthria. It is the retention of this anomalous use of dysphasia that is confusing.

In the segregation of these two forms of cortical speech defect the recognition by the subject of mistakes in words and their attempted correction should be regarded as a crucial distinction. Anatomically speaking, if the cortical motor apparatus of speech is at fault, wrong words as well as mispronounced words may be expected, but as long as their fault is recognized no comprehension difficulty need be postulated. Thus what appears at first glance to be an amnesic or receptive dysphasia may in fact be a purely motor one. It is the inability to recognize the error that makes it a true defect of comprehension.

In earlier accounts of the motor types of dysphasia an association with dyspraxia of the lips, tongue, and sometimes pharynx and larynx, has been noted. Nathan (1947) reviewed six such cases in great detail and used the term 'apraxic dysarthria' to describe them. He emphasized that 'praxia' was the cortical motor function par excellence and suggested that apraxia was in fact the basic lesion in many cases of motor dysphasia. Critchley (1960) also discussed this aspect of aphasia, but concluded that articulatory dyspraxia was an independent entity, though it might coexist with dysphasia. The detailed protocols of many cases of motor aphasia contain records of labio-lingual dyspraxia even when this is not specifically mentioned. In dyspraxia voluntary and mimetic movement cannot be carried out, while similar movements may be perfectly executed as part of an involuntary motor sequence. Dysarthria due to dyspraxia might therefore be expected to show itself most readily in mimetic and requested speech: and this is in fact its most usual setting, When flow of speech is established, the dysarthria becomes less apparent and during the course of fluent speech it is when a word has to be voluntarily sought for that mispronunciation again occurs.

Another occasional association with motor aphasia is a disordered melody, rhythm, and accentation of speech. Monrad-Krohn (1947) has termed this 'dysprosody'. It was noted and recorded in dysphasias before it was named. These cases may give the impression of someone speaking a foreign language. In Monrad-Krohn's much quoted example a Norwegian lady born and bred, who had never been out of her native land, was taken by her compatriots to be a German, because of the dysprosody following a stroke. Critchley (1962) gave further example of a similar change in English people, in whom the accent resembled that of a native Welshspeaking person. Bay (1964) emphasized its constant association with dysarthric defects and implied that it was not uncommon in such a setting, though he appears at times to be describing something less subtle than a foreign accent. In its florid form it appears to be rare.

The patient reported here had some initial lip and tongue dyspraxia and for a short while a complete anarthria. As this recovered she had a dysarthria of speech which seemed to outlast any formally elicited 
dyspraxia of lips or tongue. She also had for a time a difficulty in using the correct word both in naming objects and more occasionally in spontaneous speech. There was also evidence of slight dysgraphia, and this also had been preceded by a more extensive dyspraxia of hand movements. It is noteworthy that in each case she was at once aware of her mistakes and made some attempt to correct them. It seems reasonable to formulate her motor disability of speech and writing as basically a dyspraxic lesion.

The other striking change was the dysprosody that gave her speech a German accent. This was so marked that other patients in the ward regarded her as a foreigner. It was present when dysarthria was marked and the two tended to clear together, though the foreign accent was still obvious when dysarthria was minimal. This phenomenon is doubtless capable of further and more detailed phonetic analysis which may show it to be part of a spectrum of basically executive alterations in speech. For the present it must be noted as an unusual and bizarre aspect of motor dysphasia. It stands a little aside from the dyspraxias since it is a constant phenomenon while it lasts; and there is no equivalent here of a deficiency of voluntary movement which can be performed normally in other contexts, as is seen in dyspraxia.

The site of the lesion in the present case was well established. The angioma from which bleeding occurred was situated at the base of the Rolandic area more anterior than posterior. Haemorrhage appears to have been largely intracerebral and initial cerebrospinal fluid showed no blood staining or rise in protein. The clot cavity was subcortical and extended frontally for some $8 \mathrm{~cm}$., thus undermining part of the third and probably second frontal convolutions. It certainly impinged on Marie's 'zone lenticulaire' and its position is similar to cases described by Nathan (1947), by Bay (1962), and by Russell and Espir (1961). It was confined to the frontal lobe and there was no evidence of any more posterior extension, This is worth emphasizing because of the suggestion that dyspraxia may be associated with lesions of the supramarginal gyrus (Pussep and Levin, 1923). The final cortical defect must have been at least the area $1 \mathrm{~cm}$. by $1 \mathrm{~cm}$. by $0.75 \mathrm{~cm}$. excised at operation. However, since this was the seat of an angiomatous malformation before any speech symptoms occurred, and its function was therefore in part defective, it cannot be regarded as necessarily subserving motor speech in her case. The speech defect seems to have been produced by the subcortical haemorrhage and consequent interruption of function of overlying cortex. Recovery of function was finally complete. Rate of recovery was rapid and is more likely to have been by resumption of function in temporarily disturbed cortex than by a take-over of function by corresponding cortex of the opposing hemisphere. One can only say 'moße likely' until we know more of the time scales of improvement by local recovery and contralater: take-over. On present evidence this case lends some support to Marie's view of cortical dysarthrieg dependent on a lesion of the 'zone lenticulaire' and Nathan's view that such dysarthria is essential dyspraxic in nature. It illustrates once more the need for segregating the motor speech abnormalities cortical lesions from those involving comprehensioff Such a segregation should be maintained in the terminology of the subject and cortical dysarthr㬓 or dyspraxic dysarthria would be suitable terms $\frac{5}{10}$ describe many such motor changes. The term mot@ dysphasia is best avoided as its past usage renders its meaning equivocal.

It is of incidental interest to note that this woman suffered from migraine, but that its aura bore $\bar{r} \overrightarrow{8}$ anatomical relation to her one established vascul

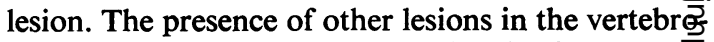
basilar circulation is not excluded by her carot angiogram.

\section{SUMMARY}

A case is reported of intracerebral haemorrig⿵ from an angioma at the base of the fissure of Rolando causing transient cortical dysarthria and dyspros\&d The case is taken as evidence in support of the oceuos rence of a cortical dysarthria, basically dyspraxio nature and due to a strictly localized frontal lesion My thanks are due to Mr. J. M. Potter for supplyin with the operation findings.

\section{REFERENCES}

Bay, E. (1962). Aphasia and non-verbal disorders of language. BraO

85, 411-426.
(1964). Principles of classification and their influence on of: concepts of aphasia. In Ciba Foundation Symposium: Disorde्fs of Language, edited by A. V. S. de Reuck and M. O'Connö, p. 122-142. Churchill, London.

Critchley, M. (1952). Articulatory defects in aphasia.J. Laryng., 66, 1-fी.

(1960). Jacksonian ideas and the future, with special referenge to aphasia. Brit. med. J., 2, 6-12.

- (1962). Livre Jubilaire de Ludo van Bogaert, p. 182. Antwerp?

Hecaen, H., and Angelergues, R. (1964). Localization of symptoms aphasia. In Ciba Foundation Symposium: Disorders of Language, edited by A. V. S. de Reuck and M. O'Connor, p. 223-256. Churchill, London.

Henschen, S. E. (1922). Klinische und anatomische Beiträge Pathologie des Gehirns, Teil 7: Uber motorische Aphasie tond Agraphie. Stockholm.

Marie, P. (1906). Revision de la question de l'aphasie. Sem. mể, (Paris), 26, 565-571.

- , and Foix, C. (1917). Les aphasies de guerre. Rev. neurol., 24 욕, 53-87.

Monrad-Krohn, G. H. (1947). Dysprosody or altered 'melody $\mathcal{B}^{\mathrm{f}}$ language'. Brain, 70, 405-415.

Nathan, P. W. (1947). Facial apraxia and apraxic dysarthria. Ibi 70, 449-478.

Pussep, L., and Levin, L. (1923). Zur Frage der Störungen d. Schluckens von apraktischem Charakter (Aphagopraxis) Z. ges. Neurol. Psychiat., 87, 441-450.

Russell, W. R., and Espir, M. L. E. (1961). Traumatic Aphasjo Oxford University Press, London. 